Article

\title{
Solid Fluorescence pH Sensors Based on 1,8-Naphthalimide Copolymers Synthesized by UV Curing
}

\author{
Jesús L. Pablos ${ }^{1,2, *(\mathbb{D})}$, Esther Hernández ${ }^{1}$, Fernando Catalina ${ }^{1}$ (D) and Teresa Corrales ${ }^{1, *(D)}$ \\ 1 Grupo Fotoquímica de Polímeros, Instituto de Ciencia y Tecnología de Polímeros (ICTP-CSIC), \\ Juan de la Cierva 3, 28006 Madrid, Spain; esther.7.h.m@gmail.com (E.H.); fcatalina@ictp.csic.es (F.C.) \\ 2 Departamento Química en Ciencias Farmacéuticas, Facultad de Farmacia, Universidad Complutense de \\ Madrid, Pl. de Ramón y Cajal, s/n, 28040 Madrid, Spain \\ * Correspondence: jesuslpa@ucm.es (J.L.P.); tcorrales@ictp.csic.es (T.C.)
}

\section{check for} updates

Citation: Pablos, J.L.; Hernández, E.; Catalina, F.; Corrales, T. Solid

Fluorescence $\mathrm{pH}$ Sensors Based on 1,8-Naphthalimide Copolymers Synthesized by UV Curing. Chemosensors 2022, 10, 73.

https://doi.org/10.3390/ chemosensors10020073

Academic Editors: Marcin Procek, Agnieszka Stolarczyk and Tomasz Jarosz

Received: 10 January 2022 Accepted: 8 February 2022 Published: 11 February 2022

Publisher's Note: MDPI stays neutral with regard to jurisdictional claims in published maps and institutional affiliations.

Copyright: (c) 2022 by the authors. Licensee MDPI, Basel, Switzerland. This article is an open access article distributed under the terms and conditions of the Creative Commons Attribution (CC BY) license (https:/ / creativecommons.org/licenses/by/ $4.0 /)$.

\begin{abstract}
Novel water-swollen photo-crosslinked membranes were obtained by copolymerization of the N-vinylpyrrolidone, butyl acrylate and ethyl methacrylate monomers functionalized with naphthalimide groups, as $\mathrm{pH}$ sensitive fluorescence probes. For that purpose, two monomers with pending naphthalimide groups anchored to ethyl methacrylate through alkyl chains with different length, were previously synthesized. The membranes were characterized using different techniques. The $\mathrm{pH}$ dependence of absorbance and the corresponding quenching of fluorescence were investigated and related to the structure of naphthalimide substituents linked to the membrane. The new solid sensors exhibited sensitive fluorescence changes at $\mathrm{pH}<3$, and lower time response was determined for membranes where the sensing group was linked through longer alkyl chain to the polymer matrix. The membranes were solid, thermally stable and easily handled to be applied as sensor materials, and showed a reversible behavior, which is an important feature for further fabrication of an economical on-site tool for the acidity detection in aqueous environments.
\end{abstract}

Keywords: photopolymerization; fluorescence probe; naphthalimide; acidity sensor

\section{Introduction}

Over the last decade, a great effort has been dedicated to the synthesis of new fluorescent sensors because of their potential application in environmental analytics and medical diagnostics, due to its high sensitivity, easy operation and rapid analysis [1]. Among different fluorescent chemosensors, naphthalimide derivatives are attracting much attention due to their photophysical, thermal, electrochemistry and electroluminescence properties, which can be modulated by introduction of different substituents at the 4 position of the naphthalimide ring [2]. In particular, the interest is focused in 1,8-naphthalimide derivatives, which have been recognized for their excellent stability and photophysical properties, visible excitation and emission exhibiting high fluorescence quantum yields. Despite the many types of naphthalimides synthesized, the design of new fluorescent sensors which exhibit high selectivity and sensitivity fluorescence, low-toxicity and stability are still challenging [3,4]. The most common approach used to develop organic molecules with tailored made photophysical and electronic properties is that of linking in their structures an electron rich donor (D) and an electron deficient acceptor (A). In the literature, a wide variety of naphthalimide based D-A conjugated systems has been reported, in which different donor moieties are attached to naphthalimide [5]. For sensor application, alkylamino substituted naphthalimide are generally developed, in which the amino group is involved in intramolecular charged transfer [6].

At the present time, the use of polymers containing fluorescent structures anchored capable of acting as sensors in the medium are of great interest from an applied point of view, because it contributes to easy reuse, increases the stability along time, and because of the thermal and chemical resistance [7]. In that sense, several strategies have been 
proposed to develop polymers containing naphthalimide moieties, which offer the excellent properties of naphthalimide as a fluorescent sensor and the properties of polymeric materials, such as thermal stability, handleability and mechanical properties. Those materials have found numerous applications for molecular detection in a variety of different areas, including sensor for cations, $\mathrm{pH}$ [8] and metal ions [9-11]; sensor for anions [12]; cell imaging [13,14]; detection of small molecules [15,16]; and recently have been tested as active components in antibacterial photodynamic therapy [17]. In previous work, photocrosslinked water-swollen acrylic membranes have been functionalized with piperazine naphthalimide derivatives for $\mathrm{Hg}^{2+}$ and $\mathrm{pH}$ detection $[18,19]$. Recently, special attention has been focused on the synthesis of polymerizable naphthalimide derivatives, which can be copolymerized with different co-monomers [20-23]. On the other hand, a new procedure for the functionalization of the surface of membranes based on a copolymer of ethylene butyl acrylate with 4-dimethylamino-N-(2-hydroxyethyl)-1,8-naphthalimide derivatives has been reported for acidity sensing [24]. In that case, the mechanism responsible for the sensory properties of naphthalimide was intramolecular charge transfer (ICT); when the aromatic amine was protonated at low $\mathrm{pH}$ values fluorescence, it was quenched.

Photopolymerization is considered a very useful method to prepare new materials due to the unique advantages of light curing technology, such as solvent free systems, temporal and spatial control, and ultrafast reactions that take place at ambient temperature avoiding thermal degradation $[25,26]$. For that reason, numerous works have been dedicated to the development of a wide variety of new photoinitiators to be applied in different formulations [27-29].

In this work, water-swollen photo-crosslinked membranes containing 4-dimethylamino naphthalimide groups are presented as materials capable of acting as fluorescent $\mathrm{pH}$ sensors. For that purpose, ethyl methacrylate monomers with pending naphthalimide group anchored through alkyl chains with different length were previously synthesized. Subsequently, monomers were copolymerized by UV irradiation with commercial monomers, Nvinylpyrrolidone (VP), butyl acrylate (BA), and ethylene glycol dimethacrylate (EGDMMA), to obtain crosslinked solid membranes for acidity detection in aqueous solution. The activity as acidity sensor of the new materials was studied by evaluating the effect of $\mathrm{pH}$ in the spectroscopic properties of absorption and fluorescence. It should be expected that the response of polymeric sensors depends on their structures, since the length of alkyl chain linked in the naphthalimide groups may affect the mobility of sensing group and for instance, the interaction of the amine group with a proton. Here, the strategy developed takes advantages of the synthesis of copolymers by UV-irradiation, which is proposed as a very promising alternative for the preparation of new polymers that allows the design of the desired properties as a function of structure and ratio of monomers selected. Then, a wide variety of very promising material sensors can be prepared with tailor-made structures, which open the possibility to work in hydrophobic or hydrophilic environments. The sensory membranes exhibited optical transparency and dimensional stability, manageability in terms of flexibility and swelling in water. In addition, the new sensors can be reused, as a consequence of their mentioned solid character and the reversibility of the process. Those characteristics are of great applied interest for the fabrication of an economical sensor for the acidity detection in aqueous environments.

\section{Materials and Methods}

\subsection{Materials}

Unless otherwise indicated, all materials were commercially available and used as received: 4-bromo-1,8-naphthalic anhydride (Aldrich, St. Louis, MO, USA, 95\%), ethanol (VWR Chemicals, Radnor, PA, USA, 99.95\%), 2-aminoethanol (Aldrich, 99\%), 2-(2-aminoethoxi)ethanol (Aldrich, 99\%), dimethylformamide (Scharlau, Cham, Germany, 99.8\%), ultrapure MilliQ water (Millipore, Burlington, MA, USA), triethylamine (Aldrich, $\geq 99 \%$ ), dichlorometane (Aldrich, $\geq 99.9 \%$ ), methacryloyl chloride (Aldrich, $\geq 97 \%$ ), coumarin 6 (Aldrich, 98\%), dimethylsulfoxide D6 (Euriso-top, Saarbrücken, Germany, 
99,8\%) deutero-hydrochloric acid ( $\mathrm{DCl}$, Aldrich 99 atom \% D), hydrochloric acid (VWR Chemicals, Radnor, PA, USA, 37\%), ethyl acetate (Aldrich, $\geq 99.5 \%$ ), hexane (Carlo Erba Reagents, Emmendingen, Germany, 99\%), toluene (Merck, Kenilworth, NJ, USA, $\geq 99.9 \%$ ), diethyl ether (Carlo Ebra, >99.8\%), 1,4-dioxan (Panreac, Darmstadt, Germany, 99\%), dimethylformamide (Aldrich, 99.9\%), chloroform (Scharlau, Barcelona, Spain, 99\%), acetone (Scharlau, 99.5\%), acetonitrile (Aldrich, $\geq 99.5 \%$ ), Irgacure 2959 (BASF, Ludwigshafen, Germany).

Monomers, 1-vinyl-2-pyrrolidone (Aldrich, $\geq 97 \%$ ), butyl acrylate (Aldrich, $\geq 99 \%$ ) and ethylene glycol dimethacrylate (Aldrich, 98\%) were distilled under vacuum to remove the inhibitor before use.

\subsection{Synthesis of the Monomers Based on 1,8-Naphtalimide Derivatives}

The two naphthalimide derivatives were synthesized with the same method and experimental conditions. The synthesis pathways, naphthalimide structures and reaction data are shown in Figure 1.
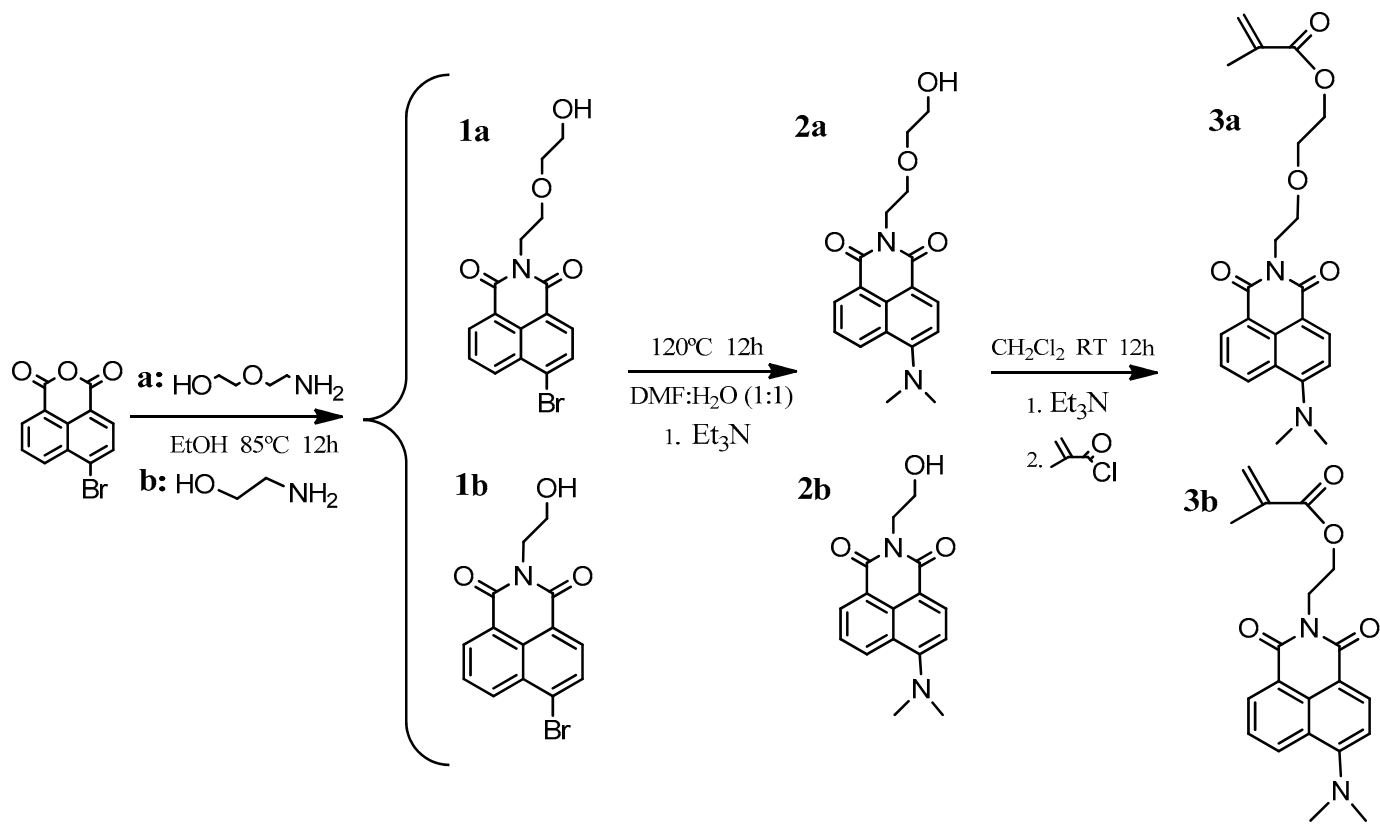

Figure 1. Synthesis of the naphthalimide derivatives.

2.2.1. Synthesis of N-(2-Hydroxyethyl)-4-bromo-1,8-naphthalimide (1a) and $\mathrm{N}$-(2-(2-Hydroxyethoxy)ethyl)-4-bromo-1,8-naphthalimide (1b)

In a pressure-resistant round flask, 4-bromo-1,8-naphthalic anhydride $(5.0 \mathrm{~g}, 0.018 \mathrm{~mol})$ and 2-aminoethanol $(1.3 \mathrm{~g}, 0.022 \mathrm{~mol})$ or 2-(2-aminoethoxy)ethanol $(2.8 \mathrm{~g}, 0.027 \mathrm{~mol})$ were mixed in ethanol $(80 \mathrm{~mL})$ and heated at $85^{\circ} \mathrm{C}$ in argon atmosphere under constant stirring for $12 \mathrm{~h}$. The resulting mixture was cooled at $5^{\circ} \mathrm{C}$. The solid separated was filtered, washed with ethanol and after dried. Yield: $73 \%$ and $54 \%$ for $1 \mathbf{a}$ and $\mathbf{1 b}$ respectively.

$\mathrm{N}$-(2-hydroxyethyl)-4-bromo-1,8-naphthalimide (compound 1a). ${ }^{1} \mathrm{H} \mathrm{RMN}\left(\delta_{\mathrm{H}} \mathrm{ppm}\right)$ $\left(400 \mathrm{MHz}, \mathrm{DMSO}-\mathrm{d}_{6}\right): \delta 8.54(\mathrm{ddd}, \mathrm{J}=11.4,7.9,1.0 \mathrm{~Hz}, 2 \mathrm{H}), 8.32(\mathrm{~d}, \mathrm{~J}=7.9 \mathrm{~Hz}, 1 \mathrm{H}), 8.20$ $(\mathrm{d}, \mathrm{J}=7.9 \mathrm{~Hz}, 1 \mathrm{H}), 7.99(\mathrm{dd}, \mathrm{J}=8.5,7.4 \mathrm{~Hz}, 1 \mathrm{H}), 4.79(\mathrm{~s}, 1 \mathrm{H}), 4.14(\mathrm{t}, \mathrm{J}=6.5 \mathrm{~Hz}, 2 \mathrm{H}), 3.63$ $(\mathrm{d}, \mathrm{J}=6.3 \mathrm{~Hz}, 2 \mathrm{H}) .{ }^{13} \mathrm{C}$ RMN $\left(\delta_{\mathrm{C}} \mathrm{ppm}\right)\left(101 \mathrm{MHz}, \mathrm{DMSO}-\mathrm{d}_{6}\right): \delta 163.03,162.99,132.52$, 131.52, 131.35, 130.91, 129.79, 128.98, 128.81, 128.37, 122.93, 122.16, 57.71, 41.97. FTIR (wavenumbers, $\mathrm{cm}^{-1}$ ): $v_{\mathrm{OH}} 3386 \mathrm{~cm}^{-1} ; v_{\mathrm{C}-\mathrm{H}} 3066 \mathrm{~cm}^{-1} ; v_{\mathrm{C}=\mathrm{O}} 1692,1658 \mathrm{~cm}^{-1} ; v_{\mathrm{N}-\mathrm{C}=\mathrm{O}}$ $1611 \mathrm{~cm}^{-1} ; v_{\mathrm{C}-\mathrm{C}} 1585,1568 \mathrm{~cm}^{-1}$.

N-(2-(2-hydroxyethoxy)ethyl)-4-bromo-1,8-naphthalimide (compound 1b). ${ }^{1} \mathrm{H}$ RMN $\left(\delta_{\mathrm{H}} \mathrm{ppm}\right)\left(400 \mathrm{MHz}, \mathrm{DMSO}-\mathrm{d}_{6}\right): \delta 8.50(\mathrm{ddd}, \mathrm{J}=17.1,7.9,0.9 \mathrm{~Hz}, 2 \mathrm{H}), 8.28(\mathrm{~d}, \mathrm{~J}=7.9 \mathrm{~Hz}$, $1 \mathrm{H}), 8.16(\mathrm{~d}, \mathrm{~J}=7.9 \mathrm{~Hz}, 1 \mathrm{H}), 7.95(\mathrm{dd}, \mathrm{J}=8.4,7.4 \mathrm{~Hz}, 1 \mathrm{H}), 4.54(\mathrm{t}, \mathrm{J}=5.2 \mathrm{~Hz}, 1 \mathrm{H}), 4.21$ 
$(\mathrm{t}, \mathrm{J}=6.5 \mathrm{~Hz}, 2 \mathrm{H}), 3.66(\mathrm{t}, \mathrm{J}=6.5 \mathrm{~Hz}, 2 \mathrm{H}), 3.47(\mathrm{~s}, 4 \mathrm{H}) .{ }^{13} \mathrm{C}$ RMN $\left(\delta_{\mathrm{C}} \mathrm{ppm}\right)(101 \mathrm{MHz}$, DMSO-d $\left.{ }_{6}\right): \delta 162.86,162.81,132.61,131.59,131.33,130.97,129.72,129.16,128.77,128.21$, 122.62, 121.84, 72.10, 66.80, 60.17. FTIR (wavenumbers, $\mathrm{cm}^{-1}$ ): $v_{\mathrm{OH}} 3386 \mathrm{~cm}^{-1} ; v_{\mathrm{C}-\mathrm{H}} 3066$ $\mathrm{cm}^{-1} ; v_{\mathrm{C}=\mathrm{O}} 1692,1658 \mathrm{~cm}^{-1} ; v_{\mathrm{N}-\mathrm{C}=\mathrm{O}} 1611 \mathrm{~cm}^{-1} ; v_{\mathrm{C}-\mathrm{C}} 1585,1568 \mathrm{~cm}^{-1}$.

2.2.2. Synthesis of $\mathrm{N}$-(2-Hydroxyethyl)-4-dimethylamine-1,8-naphthalimide (2a) and $\mathrm{N}$-(2-(2-Hydroxyethoxy)ethyl)-4-dimethylamine-1,8-naphthalimide (2b)

In a pressure-resistant round flask, compound $1 \mathrm{a}(3.0 \mathrm{~g}, 0.009 \mathrm{~mol})$ or compound $1 \mathbf{b}(3.0 \mathrm{~g}, 0.008 \mathrm{~mol})$ were mixed in DMF: $\mathrm{H}_{2} \mathrm{O}(1: 1)$ with triethylamine $(9.5 \mathrm{~g}, 0.094 \mathrm{~mol}$ or $8.3 \mathrm{~g}, 0.082 \mathrm{~mol}$, for compound $\mathbf{1 a}$ or $\mathbf{1 b}$ respectively) and heated at $120^{\circ} \mathrm{C}$ in argon atmosphere under constant stirring for $12 \mathrm{~h}$. The resulting mixture was cooled at $5{ }^{\circ} \mathrm{C}$. The solid separated was filtered, washed with milliQ water and after dried. Yield: $87 \%$ and $82 \%$ for $\mathbf{2 a}$ and $\mathbf{2} \mathbf{b}$ respectively.

$\mathrm{N}$-(2-hydroxyethyl)-4-dimethylamine-1,8-naphthalimide (compound 2a). ${ }^{1} \mathrm{H}$ RMN $\left(\delta_{\mathrm{H}} \mathrm{ppm}\right)\left(400 \mathrm{MHz}, \mathrm{DMSO}-\mathrm{d}_{6}\right): \delta 8.53-8.40(\mathrm{~m}, 2 \mathrm{H}), 8.31(\mathrm{~s}, 1 \mathrm{H}), 7.74(\mathrm{~d}, \mathrm{~J}=1.1 \mathrm{~Hz}, 1 \mathrm{H})$, $7.20(\mathrm{~d}, \mathrm{~J}=8.3 \mathrm{~Hz}, 1 \mathrm{H}), 4.79(\mathrm{~s}, 1 \mathrm{H}), 4.13(\mathrm{~s}, 2 \mathrm{H}), 3.59(\mathrm{~d}, \mathrm{~J}=6.3 \mathrm{~Hz}, 2 \mathrm{H}), 3.08(\mathrm{~s}, 6 \mathrm{H}) .{ }^{13} \mathrm{C}$ RMN $\left(\delta_{\mathrm{C}} \mathrm{ppm}\right)\left(75 \mathrm{MHz}, \mathrm{DMSO}-\mathrm{d}_{6}\right): \delta 163.76,163.11,156.50,132.20,131.42,130.50,129.64$, $125.00,124.23,122.45,113.50,112.99,57.87,44.39$. FTIR (wavenumbers, $\mathrm{cm}^{-1}$ ): $v_{\mathrm{OH}} 3474$ $\mathrm{cm}^{-1} ; v_{\mathrm{C}=\mathrm{O}} 1680,1628 \mathrm{~cm}^{-1} ; v_{\mathrm{C}-\mathrm{C}} 1575 \mathrm{~cm}^{-1}$.

$\mathrm{N}$-(2-(2-hydroxyethoxy)ethyl)-4-dimethylamine-1,8-naphthalimide (compound $\mathbf{2 b}$ ). ${ }^{1} \mathrm{H}$ RMN $\left(\delta_{\mathrm{H}} \mathrm{ppm}\right)(400 \mathrm{MHz}$, DMSO-d6): $\delta 8.52-8.36(\mathrm{~m}, 2 \mathrm{H}), 8.29(\mathrm{~d}, \mathrm{~J}=8.3 \mathrm{~Hz}, 1 \mathrm{H}), 7.71$ $(\mathrm{dd}, \mathrm{J}=8.5,7.3 \mathrm{~Hz}, 1 \mathrm{H}), 7.16(\mathrm{~d}, \mathrm{~J}=8.4 \mathrm{~Hz}, 1 \mathrm{H}), 4.54(\mathrm{t}, \mathrm{J}=5.2 \mathrm{~Hz}, 1 \mathrm{H}), 4.20(\mathrm{t}, \mathrm{J}=6.6 \mathrm{~Hz}, 2 \mathrm{H})$, $3.62(\mathrm{t}, \mathrm{J}=6.6 \mathrm{~Hz}, 2 \mathrm{H}), 3.46(\mathrm{~d}, \mathrm{~J}=2.1 \mathrm{~Hz}, 4 \mathrm{H}), 3.07(\mathrm{~s}, 6 \mathrm{H}) .{ }^{13} \mathrm{C} \mathrm{RMN}\left(\delta_{\mathrm{C}} \mathrm{ppm}\right):(75 \mathrm{MHz}$, DMSO) $\delta 163.63,162.94,162.30,156.55,132.29,131.55,130.57,129.59,124.93,124.13,122.17$, $113.11,112.91,72.10,66.99,60.18,44.36$. FTIR (wavenumbers, $\mathrm{cm}^{-1}$ ): $v_{\mathrm{OH}} 3386 \mathrm{~cm}^{-1} ; v_{\mathrm{C}-\mathrm{H}}$ $3066 \mathrm{~cm}^{-1} ; v_{\mathrm{C}=\mathrm{O}} 1692,1658 \mathrm{~cm}^{-1} ; v_{\mathrm{N}-\mathrm{C}=\mathrm{O}} 1611 \mathrm{~cm}^{-1} ; v_{\mathrm{C}-\mathrm{C}} 1585,1568 \mathrm{~cm}^{-1}$.

2.2.3. Synthesis of 2-(2-(6-(Dimethylamino)-1,3-dioxo-1H-benzo[de]isoquinolin-2(3H)-yl) ethoxy)ethyl Methacrylate (3a) and 2-(6-(Dimethylamino)-1,3-dioxo-1Hbenzo[de]isoquinolin-2(3H)-yl)ethyl Methacrylate (3b)

In a pressure-resistant round flask, compound $\mathbf{2 a}(2.0 \mathrm{~g} ; 0.007 \mathrm{~mol})$ or compound $\mathbf{2 b}$ $(3.0 \mathrm{~g}$; $0.009 \mathrm{~mol})$ was dissolved in dichloromethane $(25 \mathrm{~mL})$ at $0{ }^{\circ} \mathrm{C}$ (ice bath). Afterwards, $2.8 \mathrm{~g}(0.028 \mathrm{~mol}) / 3.7 \mathrm{~g}(0.036 \mathrm{~mol})$ (for compound $\mathbf{3 a}$ or $\mathbf{3 b}$ respectively, dissolved in 5 $\mathrm{mL}$ of dichloromethane) of triethylamine (TEA) was added to the solution. The mixture was stirred for $15 \mathrm{~min}$ and $1.5 \mathrm{~g}$, $(0.014 \mathrm{~mol}) / 1.9 \mathrm{~g}(0.018 \mathrm{~mol})$ of methacryloyl chloride (dissolved in $5 \mathrm{~mL}$ of dichloromethane) was added dropwise, and it was stirred at $\mathrm{rt}$ for 12 $h$. The solution was dried in a vacuum and the residue obtained was dissolved in acetone and precipitated in water. The solid obtained was filtered and washed with water. The product ( $3 \mathbf{a}$ or $\mathbf{3 b}$ ) was collected and dried at $25{ }^{\circ} \mathrm{C}$ overnight. Yield: $78 \%$ and $74 \%$ for $3 \mathbf{a}$ and $3 b$ respectively.

2-(2-(6-(dimethylamino)-1,3-dioxo-1H-benzo[de]isoquinolin-2(3H)-yl)ethoxy)ethyl methacrylate (Compound $3 \mathrm{a}) .{ }^{1} \mathrm{H} \mathrm{RMN}\left(\delta_{\mathrm{H}} \mathrm{ppm}\right)\left(400 \mathrm{MHz}, \mathrm{DMSO}-\mathrm{d}_{6}\right): \delta 8.56-8.41$ $(\mathrm{m}, 2 \mathrm{H}), 8.34(\mathrm{~d}, \mathrm{~J}=8.3 \mathrm{~Hz}, 1 \mathrm{H}), 7.84-7.70(\mathrm{~m}, 1 \mathrm{H}), 7.21(\mathrm{~d}, \mathrm{~J}=8.4 \mathrm{~Hz}, 1 \mathrm{H}), 5.91(\mathrm{~s}, 1 \mathrm{H})$, $5.59(\mathrm{~s}, 1 \mathrm{H}), 4.37(\mathrm{t}, \mathrm{J}=4.5 \mathrm{~Hz}, 4 \mathrm{H}), 3.10(\mathrm{~s}, 6 \mathrm{H}), 1.76(\mathrm{~s}, 3 \mathrm{H}) .{ }^{13} \mathrm{C}$ RMN $\left(\delta_{\mathrm{C}} \mathrm{ppm}\right)(75$ MHz, DMSO-d $\left.{ }_{6}\right): \delta 166.46,163.82,163.10,156.70,135.71,132.41,131.75,130.68,129.74$, $125.79,125.04,124.21,122.19,113.02,61.62,44.39$. FTIR (Wavenumbers, $\mathrm{cm}^{-1}$ ): $v_{\mathrm{C}=\mathrm{O}} 1680$, $1628 \mathrm{~cm}^{-1} ; v_{\mathrm{C}-\mathrm{C}} 1575 \mathrm{~cm}^{-1}$.

2-(6-(dimethylamino)-1,3-dioxo-1H-benzo[de]isoquinolin-2(3H)-yl)ethyl methacrylate (compound $3 b) .{ }^{1} \mathrm{H}$ RMN $\left(\delta_{\mathrm{H}} \mathrm{ppm}\right)\left(400 \mathrm{MHz}, \mathrm{DMSO}_{-} \mathrm{d}_{6}\right): \delta 8.53(\mathrm{~d}, \mathrm{~J}=1.0 \mathrm{~Hz}, 1 \mathrm{H}), 8.45$ $(\mathrm{d}, \mathrm{J}=8.3 \mathrm{~Hz}, 1 \mathrm{H}), 8.34(\mathrm{~d}, \mathrm{~J}=8.3 \mathrm{~Hz}, 1 \mathrm{H}), 7.81-7.70(\mathrm{~m}, 1 \mathrm{H}), 7.22(\mathrm{~d}, \mathrm{~J}=8.4 \mathrm{~Hz}, 1 \mathrm{H}), 5.86$ $(\mathrm{s}, 1 \mathrm{H}), 5.50(\mathrm{~s}, 1 \mathrm{H}), 4.22(\mathrm{~d}, \mathrm{~J}=6.1 \mathrm{~Hz}, 2 \mathrm{H}), 4.19-4.08(\mathrm{~m}, 2 \mathrm{H}), 3.79-3.58(\mathrm{~m}, 4 \mathrm{H}), 3.10(\mathrm{~s}$, $6 \mathrm{H}), 1.73(\mathrm{~s}, 3 \mathrm{H}) .{ }^{13} \mathrm{C}$ RMN $\left(\delta_{\mathrm{C}} \mathrm{ppm}\right)\left(75 \mathrm{MHz}, \mathrm{DMSO}-\mathrm{d}_{6}\right): \delta 163.63,162.94,162.30,156.55$, $132.29,131.55,130.57,129.59,124.93,124.13,122.17,113.11,112.91,72.10,66.99,60.18,44.36$. FTIR (wavenumbers, $\mathrm{cm}^{-1}$ ): $v_{\mathrm{C}-\mathrm{H}} 3066 \mathrm{~cm}^{-1} ; v_{\mathrm{C}=\mathrm{O}} 1692,1658 \mathrm{~cm}^{-1} ; v_{\mathrm{N}-\mathrm{C}=\mathrm{O}} 1611 \mathrm{~cm}^{-1}$; $v_{\mathrm{C}-\mathrm{C}} 1585,1568 \mathrm{~cm}^{-1}$. 


\subsection{Characterization and Procedures}

All compounds and materials synthetized were characterized by several techniques.

Firstly, the structure of all compounds obtained was confirmed through their ${ }^{1} \mathrm{H}-\mathrm{NMR}$ and ${ }^{13} \mathrm{C}$-NMR spectra, which were recorded on a Varian-Mercury $400 \mathrm{MHz}$ using DMSO- $\mathrm{d}_{6}$ as solvent. Furthermore, all structures along with their presence in sensory materials were confirmed by registering their ATR-FTIR spectra using a BXFTIR Perkin Elmer Spectrometer and a MIRacle ${ }^{\mathrm{TM}}$ ATR accessory coupled (PIKE Technologies).

Secondly, thermal properties of sensory materials were analyzed. For that, Thermogravimetric analysis (TGA) was carried out (TGA Q-500 TA Instruments in standard conditions under nitrogen atmosphere from 25 to $600{ }^{\circ} \mathrm{C}$ at a heating rate of $10^{\circ} \mathrm{C} \cdot \mathrm{min}^{-1}$ ). Additionally, to determine the values of glass transitions (Tg) from second heating scan, Differential scanning calorimetry (DSC) was performed in a Mettler DSC 823 calorimeter, fixing the following experimental conditions: nitrogen atmosphere, heated from $-60{ }^{\circ} \mathrm{C}$ to $180{ }^{\circ} \mathrm{C}$ at a heating rate of $10^{\circ} \mathrm{C} \cdot \mathrm{min}^{-1}$ and then cooled to $25^{\circ} \mathrm{C}$.

Experiments related to determine the spectroscopic characteristics of sensory monomers and materials were carried out. For this purpose, UV and fluorescence spectra were obtained by using a Perkin Elmer Lambda 35 UV spectrometer and a Perkin Elmer LS 55 fluorimeter respectively.

A strategic parameter in the design of solid sensory materials is the swelling degree (SD), which show the hydrophilicity of materials. This parameter is crucial in the diffusion of target molecules into the solvent rich membrane. Swelling degree (SD) was determined in water as solvent, and was determined by immersing dried sample films into deionized water at $25^{\circ} \mathrm{C}$ for $24 \mathrm{~h}$. The samples were immediately weighed $\left(\mathrm{W}_{\mathrm{s}}\right)$ and then they were completely dried and weighed again $\left(\mathrm{W}_{\mathrm{d}}\right)$. Finally, the SD percentage was calculated by using the following equation: $\mathrm{SD}(\%)=\left(\left(\mathrm{W}_{\mathrm{s}}-\mathrm{W}_{\mathrm{d}}\right) / \mathrm{W}_{\mathrm{d}}\right) \times 100$.

Membranes preparation was undertaken in a Biolink ${ }^{\mathrm{TM}}$ BLX-365 (Vilbert Lourmat ${ }^{\mathrm{TM}}$ ), by Photopolymerization reactions of a mixture of monomers, N-vinylpyrrolidone (VP, 60\% $\mathrm{mol}$ ), butyl acrylate (BA, 40\% mol), ethylene glycol dimethacrylate (EGDMMA, 5\%mol) as crosslinking agent, monomers previously synthesized $\mathbf{3 a}$ or $\mathbf{3 b}(0.01 \% \mathrm{~mol})$, and Irgacure 659 (1 wt.\%) as photo-initiator. The homogenous mixture was degassed by argon bubbling for $15 \mathrm{~min}$ and injected into a previously degassed silanized glass mould. After $30 \mathrm{~min}$ of irradiation at $365 \mathrm{~nm}$ (dose $20 \mathrm{~J} \mathrm{~cm}^{-2}$ ), the crosslinked membranes were demolded and conditioned at room temperature during $12 \mathrm{~h}$ under argon atmosphere. Then, membranes were washed several times with ethanol and dried under vacuum at $40{ }^{\circ} \mathrm{C}$ to remove the unreacted monomers. Following that procedure, membranes $\mathrm{M}_{3 a}$ and $\mathrm{M}_{3 b}(50 \mu \mathrm{m}$ of thickness) were obtained. In addition, a reference membrane $\mathrm{M}_{\text {ref }}$ was prepared in absence of fluorescent monomer. The chemical structure of new copolymers and photographs showing the self-standing sensory membranes are depicted in Figure 2.
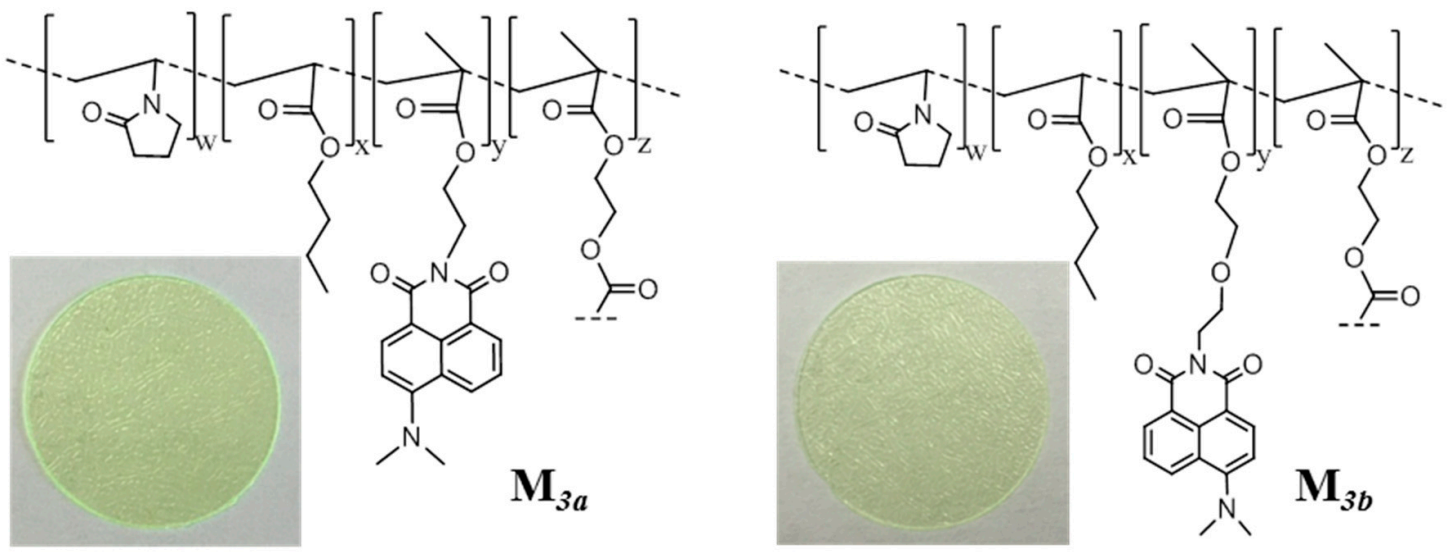

Figure 2. Chemical structure of membranes and photographs showing the self-standing sensory membranes, $\mathrm{M}_{3 a}$ (left) and $\mathrm{M}_{3 b}$ (right). 
Determination of $\mathrm{pH}$ values were carried out with a Mettler Toledo SevenGo Duo Pro meter with an InLab Expert Pro ISM-ID67 electrode. The sensing analysis determined from the solutions of naphthalimide monomers and functionalized membranes was performed using $\mathrm{HCl}$ solutions in the mixture water:ethanol (4:1) as solvent. The titration curves obtained from UV/Vis and fluorescence emission spectra were obtained as follows for monomer solution and solid sensory material, respectively. The titration with naphthalimide derivatives was carried out in solution (water:ethanol 4:1) with hydrochloric acid. The acidity of the media was increased from $\mathrm{pH} 5$ to $\mathrm{pH} 0.5$ by adding diluted hydrochloric acid. The general procedure followed after each addition was to allow the equilibration of solutions for $10 \mathrm{~min}$ to ensure a stable value of $\mathrm{pH}$. Finally, the $\mathrm{pH}$ was measured and the $\mathrm{UV} /$ Vis and fluorescence spectra were registered.

Concerning the functionalized cross-linked sensory membranes, the materials were cut into right-angled squares of $1 \times 4 \mathrm{~cm}$ and them immersed into $100 \mathrm{~mL}$ of required solvent (water and hydrochloric acid solutions) using a homemade support. To study the effect of increasing acidity medium, several vials containing $50 \mathrm{~mL}$ of hydrochloric acid of concentrations ranging from $\mathrm{pH} 5$ to $\mathrm{pH} 0.5$ were prepared. Consequently, sensory materials squares were submerged in the vials, (conditioning time, $20 \mathrm{~min}$ ) and finally, registering the UV/Vis and fluorescence spectra for each $\mathrm{pH}$ value.

Finally, the fluorescence detection of acidic vapors was performed by adding $100 \mu \mathrm{L}$ of $\mathrm{HCl}(12 \mathrm{M})$ over a cotton fragment placed in the bottom of a sealed spectrophotometric cuvette to avoid direct contact with the sensory membranes. Then, the fluorescence spectra where registered every five minutes.

\section{Results}

In this work, two monomers were synthesized with pending naphthalimide group attached to ethyl methacrylate by alkyl chain with different length, 2-hydroxyethyl (monomer 3a) and 2-(2-hydroxyethoxy)ethyl (monomer 3b), Figure 1. Then, membranes containing naphthalimide derivatives were developed by photopolymerization of a mixture of monomers, N-vinylpyrrolidone (VP), butyl acrylate (BA), ethylene glycol dimethacrylate (EGDMMA) and monomer previously synthesized $\mathbf{3 a}$ or $\mathbf{3 b}$ (membranes $\mathrm{M}_{3 a}$ and $\mathrm{M}_{3 b}$ respectively), to assess the influence of the alkyl chain length on their properties, Figure 2. In addition, a reference membrane Mref was prepared in absence of fluorescent monomer and crosslinked with EGDMMA, Table 1. The procedure is described in Section 2.3.

Table 1. Properties of membranes: $T_{5}$ and $T_{\max }$ obtained from TGA, Tg obtained from DSC, swelling degree in water (SD).

\begin{tabular}{ccccc}
\hline Materials & $\mathbf{T}_{\mathbf{5}}\left({ }^{\circ} \mathbf{C}\right)$ & $\mathbf{T}_{\max }\left({ }^{\circ} \mathbf{C}\right)$ & $\mathbf{T g}\left({ }^{\circ} \mathbf{C}\right)$ & SD (\%) \\
\hline $\mathbf{M}_{r e f}$ & 335 & 407 & 60 & 38 \\
$\mathbf{M}_{3 a}$ & 340 & 409 & 59 & 39 \\
$\mathrm{M}_{3 b}$ & 342 & 409 & 54 & 38 \\
\hline
\end{tabular}

\subsection{Characterization of Sensory Materials}

The materials were characterized by ATR-FTIR spectroscopy. The spectrum of membranes showed the characteristic peaks of comonomers, amide groups and butyl acrylate moieties present in their chemical structure, $v_{\mathrm{C}=\mathrm{O}}$ lactam, $1675 \mathrm{~cm}^{-1}, v_{\mathrm{C}=\mathrm{O}}$ ester $1725 \mathrm{~cm}^{-1}$; $v_{\mathrm{C}-\mathrm{O}}\left(\mathrm{O}-\mathrm{CH}_{2}-\right)$ ester $1161 \mathrm{~cm}^{-1}$. The content of naphthalimide in sensory membranes, $\mathrm{M}_{3 a}$ and $\mathrm{M}_{3 b}$, was quantitatively determined by UV-vis spectroscopy $\left(1.6 \times 10^{-4} \mathrm{M}\right)$ at the peak maximum of the absorption band and using the absorption coefficient of naphthalimide $3 \mathbf{a}$ in water:ethanol $(4: 1 w / w)\left(\varepsilon_{446}=10.2 \times 10^{3} \mathrm{~mol}^{-1} \mathrm{Lcm}^{-1}\right)$ previously calculated, Table 2 . 
Table 2. Parameters determined by UV-VIS absorption and fluorescence spectroscopies for $\mathbf{3 a}$ and $\mathbf{3 b}$ naphthalimide in solution and $\mathrm{M}_{3 a}$ and $M_{3 b}$ membrane sensor.

\begin{tabular}{|c|c|c|c|c|c|}
\hline & \multirow{2}{*}{$\lambda_{\mathrm{ABS}}(\mathrm{nm})$} & \multirow{2}{*}{$\log \varepsilon$} & \multirow{2}{*}{$\lambda_{\mathrm{FLU}}(\mathrm{nm})$} & \multicolumn{2}{|c|}{$\phi F L U$} \\
\hline & & & & $\mathrm{H}_{2} \mathrm{O}: \mathrm{EtOH}$ & Hexane \\
\hline Derivative $\mathbf{3 a}$ & 446 & 4.01 & 546 & 0.01 & 0.72 \\
\hline Derivative $3 \mathbf{b}$ & 443 & 4.01 & 546 & 0.03 & 0.77 \\
\hline Membrane $\mathrm{M}_{3 a}$ & 428 & - & 520 & - & - \\
\hline Membrane $\mathrm{M}_{3 b}$ & 428 & - & 520 & - & - \\
\hline
\end{tabular}

The thermogravimetric analysis was undertaken to determine the thermal stability of materials. All membranes exhibited two peaks in the TGA analysis. For $\mathrm{M}_{\text {ref }}$, the highest weight loss rate occurred at $407^{\circ} \mathrm{C}$ that corresponds to the degradation of acrylic components and the second peak at $438{ }^{\circ} \mathrm{C}$ that is attributed to the lactam subgroup degradation [30]. For $\mathrm{M}_{3 a}$ and $\mathrm{M}_{3 b}$ similar behavior was observed, even if slight increase on weight loss temperatures $\mathrm{T}_{5}$ was detected, Table 1.

For all cross-linked polymer, the glass transition was determined by DSC, and was slightly dependent on the network nature, Table 1 . The comparison of the two sensory membranes allowed determining the decrease of $\mathrm{Tg}$ when monomer $\mathbf{3 b}$ was included instead of monomer 3a. That fact would be related to the larger size of alkyl chain, which favored greater polymer chain mobility, and as a result, the glass transition temperature decreases. In general, the hydrophilic character of all the membranes was confirmed, since the degree of swelling (SD) in water reach values of $40 \%$, which is adequate for their application as solid sensors in water, Table 1.

The functionalized membranes with naphthalimide groups were solids, and exhibited excellent properties for sensor applications, such as thermal stability, swelling in water, good manageability in terms of flexibility, optical transparency and dimensional stability, as it is showed in Figure 2. This behavior, as will be seen in the next section, allowed the reproducibility on the response to external environmental changes of $\mathrm{pH}$.

\subsection{Spectroscopic Characteristic of Monomers ( $3 \mathbf{a}$ and $\mathbf{3 b})$ and Membranes $\left(M_{3 a}\right.$ and $\left.M_{3 b}\right)$}

Firstly, the absorbance of monomers based on naphthalimide was studied in water:ethanol $(4: 1 \mathrm{v} / v)$ solution. Spectra exhibited absorption maxima around $445 \mathrm{~nm}$, Table 2 . That band has been attributed to intramolecular electron charge transfer (ICT), which is associated with electron donor-acceptor interaction which takes place between the unbound electron pair of the nitrogen atom at $\mathrm{C}-4$ position and the electron-accepting pericarboiximide groups [24]. The fluorescence spectra showed emission maxima at $546 \mathrm{~nm}$, and the fluorescence quantum yield was low in polar media but was drastically increased to 0.77 in hexane, which agrees with the results obtained by other authors [31]. When the naphthalimides are bonded to the macromolecular chain by photopolymerization, the absorption and fluorescence maxima exhibited a marked hypsochromic shift of 15-25 nm and maintaining the Stokes shift. Regardless on their structure, the absorbance and fluorescence spectra of $\mathrm{M}_{3 a}$ and $\mathrm{M}_{3 b}$, showed a peak at $428 \mathrm{~nm}$ and $520 \mathrm{~nm}$ Figure 3. The fluorescence observed in sensory membranes was fully attributable to naphthalimide moieties, since negligible emission was detected in $\mathrm{M}_{\text {ref }}$. Because of difference between the fluorescence standard used in solution and the functionalized membranes, the fluorescence quantum yields of $\mathrm{M}_{3 a}$ and $\mathrm{M}_{3 b}$, were no determined. 

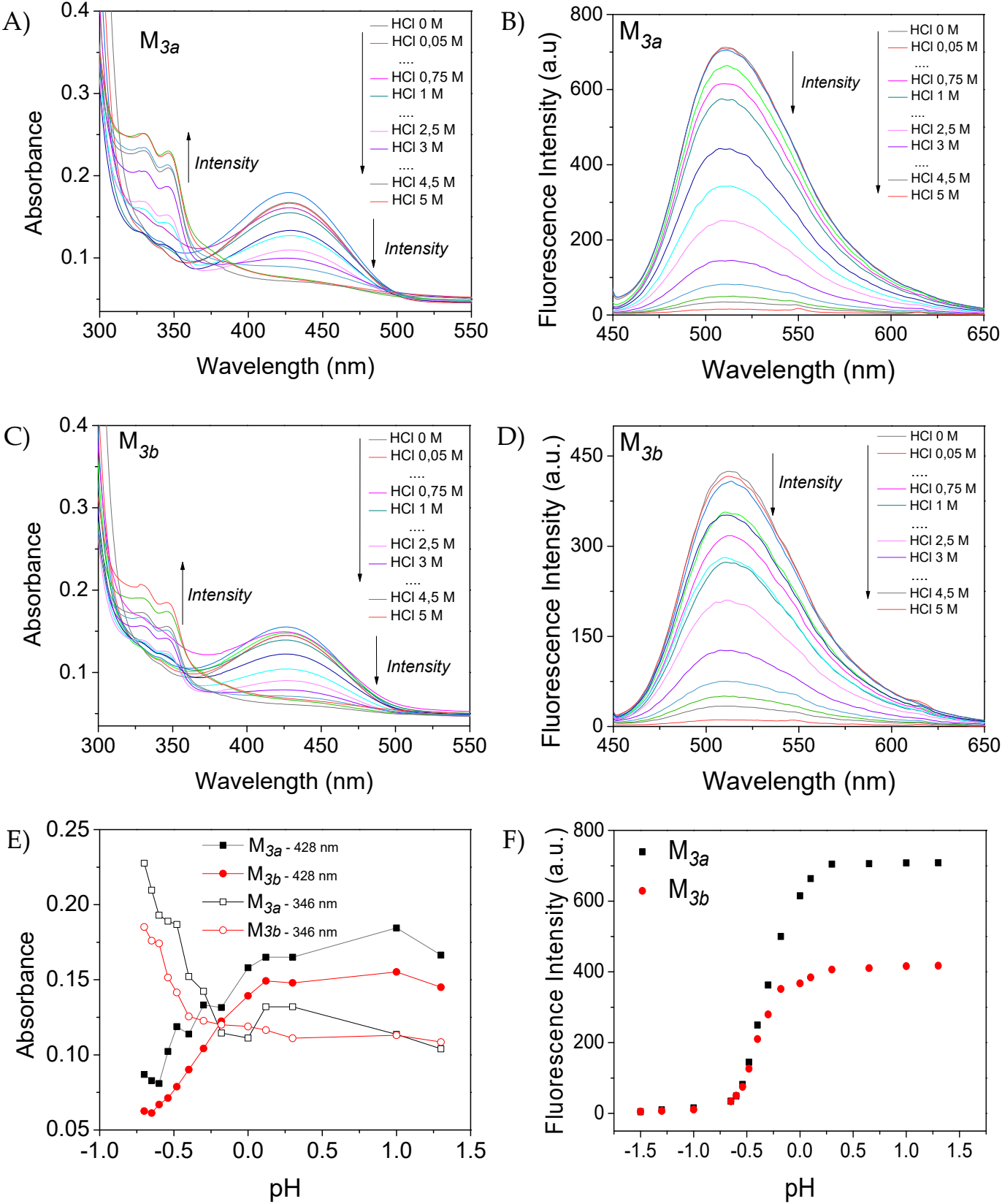

Figure 3. Absorption of $\mathrm{M}_{3 a}(\mathbf{A})$ and $\mathrm{M}_{3 b}(\mathbf{C})$ and fluorescence of $\mathrm{M}_{3 a}(\mathbf{B})$ and $\mathrm{M}_{3 b}(\mathbf{D})$ as a function of acid media. Comparison of the absorption (E) and fluorescence $(\mathbf{F})$ changes with $\mathrm{pH}$ for $\mathrm{M}_{3 a}$ and $\mathrm{M}_{3 b}$.

The effect of $\mathrm{pH}$ on the absorption and fluorescence properties of membranes has been studied, Figure 3. Upon acidification, the maxima intensity of the absorption band decreased. A remarkable decrease on the fluorescence intensity of the emission maximum was observed by decreasing the $\mathrm{pH}$ from 0.5 to -0.5 . That was attributed to the electron withdrawing effect when the aromatic amine of the naphthalimide derivative is protonated at low $\mathrm{pH}$ values, which leads to fluorescence quenching.

The $\mathrm{pH}$ dependence of the emission intensity (I) of naphthalimide copolymer films at a given wavelength was analyzed, and the $\mathrm{pKa}$ was determined according to the equation: $\log \left[\left(\mathrm{I}_{\mathrm{FLU}-\mathrm{acid}}-\mathrm{I}\right) /\left(\mathrm{I}-\mathrm{I}_{\mathrm{FLU}}\right)\right]=\mathrm{pH}-\mathrm{pKa}$. The $\mathrm{pKa}$ for $\mathrm{M}_{3 a}$ has a negative value $(-0.25)$ slightly lower than that of $\mathrm{M}_{3 b}(-0.19)$, which means that dimethylamine protonation takes places at slightly lower $\mathrm{pH}$ than that observed for $\mathrm{M}_{3 b}$. It would be associated to the longer alkyl chain bonding naphthalimide to the polymer chain in $\mathrm{M}_{3 b}$, which enabled a higher $\mathrm{pKa}$, as it is more easily protonated than in $\mathrm{M}_{3 a}$, where accessibility to naphthalimide 
would be more restricted. Those results showed that the new materials act as extreme acidity sensor by their absorbance and fluorescence characteristics.

It must be pointed out that the presence of longer alkyl chain in naphthalimide derivatives linked to polymer, results in lower emission intensity, as it is showed in Figure 3 for $\mathrm{M}_{3 b}$ in comparison to $\mathrm{M}_{3 a}$. It would be in accordance with the results described by other authors [3], where naphthalimide showed spontaneous tendency to undergo fluorescence self-quenching in hydrogel systems because of their aggregation, which would be more favored in $\mathrm{M}_{3 b}$ because of their enhanced mobility. Otherwise, it has been described that the protonation of naphthalimide moieties grafted on polymer chains result in the electrostatic repulsion among naphthalimide fluorophores. Thus, it may be assumed that the changes in the emission intensity of the copolymers at different $\mathrm{pH}$, may be a consequence of several factors, the presence of aggregation induced quenching effect, apart from the electron withdrawing effect which leads to fluorescence quenching when naphthalimide derivative is protonated at low $\mathrm{pH}$ values. The results obtained evidence the significant influence of linker in the structure of naphthalimide, and also the content of fluorescent groups on the response of polymer sensors. It is concluded that interactions of naphthalimide groups cannot be disregarded, in addition to those expected of $\mathrm{pH}$.

The reversibility of the acid detection process by $\mathrm{M}_{3 a}$ and $\mathrm{M}_{3 b}$ was evaluated by alternating their immersion in $\mathrm{HCl}(12 \mathrm{M})$ solution and in pure water. In all cycles, before to the next measurement, the fluorescence intensity of the membrane reached again the original value. Three cycles were carried out as it is shown in Figure 4, and no noticeable hysteresis effect was observed in the solid sensors. Moreover, the stability of the materials was analyzed after $24 \mathrm{~h}$ of treatment in acid media, and total recovery was detected.

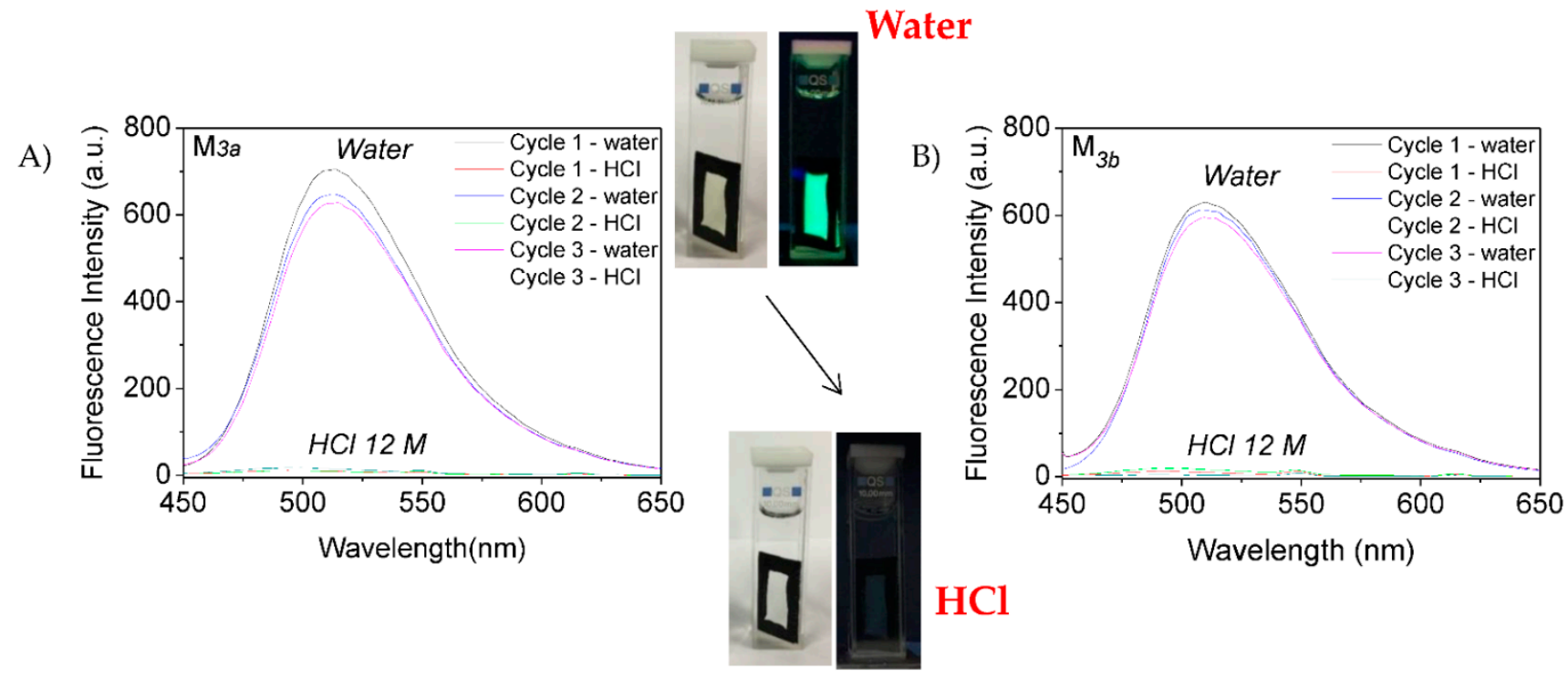

Figure 4. Reversibility of $\mathrm{M}_{3 a}(\mathrm{~A})$ and $\mathrm{M}_{3 b}$ (B) by immersion in $\mathrm{HCl}(12 \mathrm{M})$ followed by washing in pure water. Photographs showing the fluorescence change of films immersed in water or HCL.

The response times to $\mathrm{pH}$ of the fluorescence spectra of photocrosslinked materials $\mathrm{M}_{3 a}$ and $\mathrm{M}_{3 b}$ were studied, since they are dependent upon the proton permeability into the membranes. The obtained results are plotted in Figure 5. The fluorescence of the membranes to acidic media exhibited a high sensitivity to $\mathrm{pH}$ in water, and reached the equilibrium in less than $5 \mathrm{~min}$. The time response of $\mathrm{M}_{3 a}\left(3 \mathrm{~min}\right.$ ) is higher than those of $\mathrm{M}_{3 b}$ ( $2 \mathrm{~min}$ ), where the sensing group is linked through longer alkyl chain to the polymer matrix that impair the mobility, and the interaction of the amine group with a proton should be much easier. In general, the obtained values are lower or in the order of $\mathrm{pH}$ sensor immobilized in polymer matrix described in the literature $[18,32,33]$. 

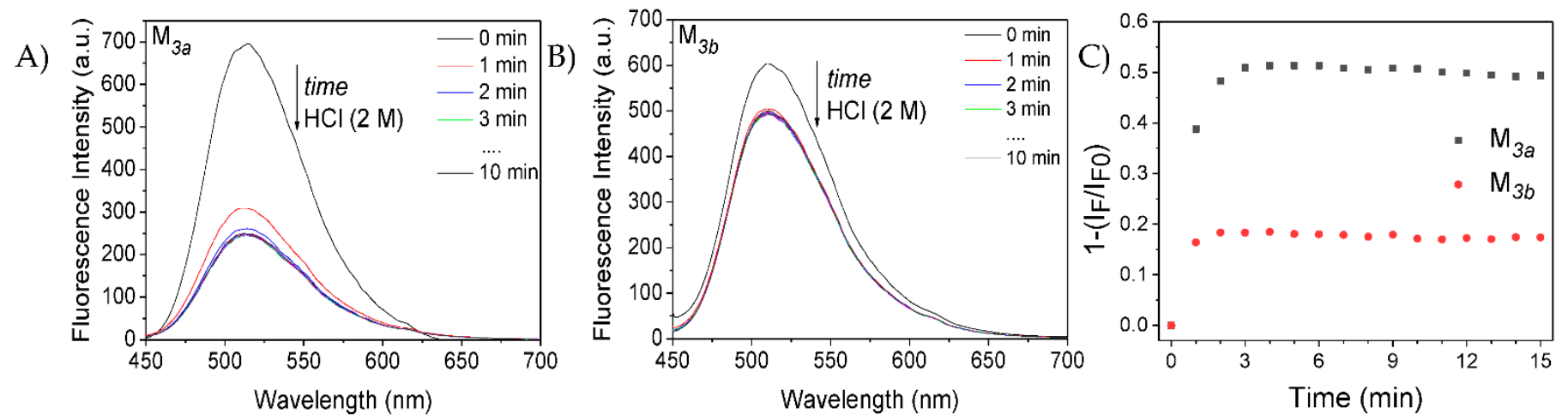

Figure 5. Fluorescence spectra of the functionalized membranes $\mathrm{M}_{3 a}(\mathbf{A})$ and $\mathrm{M}_{3 b}(\mathbf{B})$ and Time response $(\mathbf{C})$ to $\mathrm{pH}$.

Evidence for the interaction of the naphthalimide with acidic media was obtained via ${ }^{1} \mathrm{H}$ NMR spectroscopy of a $\mathrm{D}_{2} \mathrm{O} / \mathrm{DMSOD}_{6}$ (1:2) and hydrochloric acid (DCL 37\%) solution of derivatives $\mathbf{3} \mathbf{a}$ and $\mathbf{3} \mathbf{b}$, Figure 6.

A)
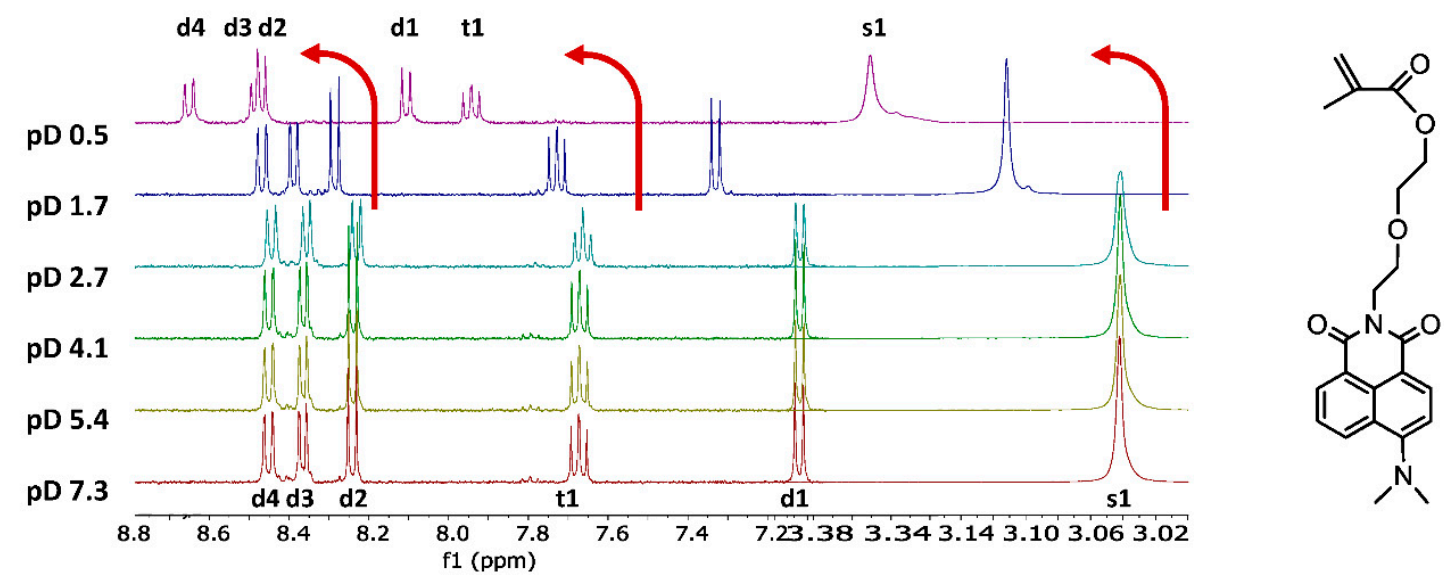

B)

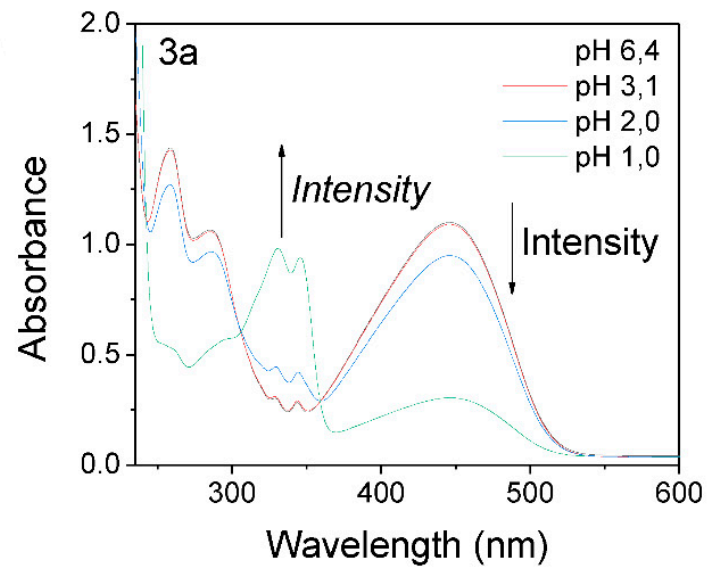

C)

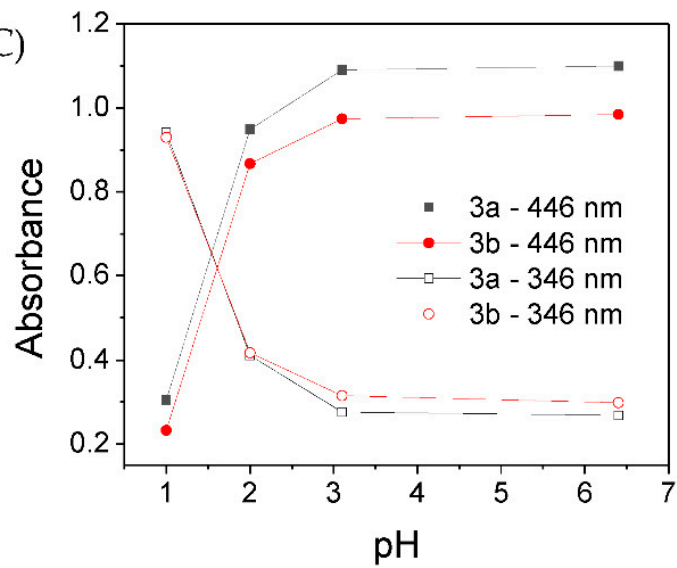

Figure 6. (A) ${ }^{1} \mathrm{H}$ NMR spectrum of compound $3 \mathbf{b}$ in $\mathrm{D}_{2} \mathrm{O} / \mathrm{DMSO}-\mathrm{d}_{6}(1 / 4)$ (1:2) and hydrochloric acid (DCL 37\%) solution; (B) absorbance spectra of 3a at different $\mathrm{pH}$; and (C) Comparison of the absorption changes with $\mathrm{pH}$ for $\mathbf{3} \mathbf{a}$ and $\mathbf{3} \mathbf{b}$.

The protonation induced an increase of the electron density resulting a downfield shift of the signal of the naphthalimide ring protons [7.12 to $8.12 \mathrm{ppm}(1 \mathrm{H}, \mathrm{d} 1) ; 7.58$ to $7.5 \mathrm{ppm}$ $(1 \mathrm{H}, \mathrm{t} 1) ; 8.25$ to $8.47 \mathrm{ppm}(1 \mathrm{H}, \mathrm{d} 2), 8.3$ to $8.50 \mathrm{ppm}(1 \mathrm{H}, \mathrm{d} 3) ; 8.46$ to $8.65 \mathrm{ppm}(1 \mathrm{H}, \mathrm{d} 4)]$, and dimethylamine group protons [3.04 to $3.40 \mathrm{ppm}(6 \mathrm{H}, \mathrm{s} 1)]$, upon decreasing of $\mathrm{pD}$ from a 
2.7 value, as it is shown, as example, for $\mathbf{3 b}$ in Figure 6A. That result correlated with the decrease of the maxima intensity of the absorption band for $\mathbf{3} \mathbf{a}$ and $\mathbf{3} \mathbf{b}$ upon acidification, Figure 6B,C.

As expected, the $\mathrm{pKa}$ for naphthalimide monomers determined from the absorbance change are higher (around 1.6) than those obtained for naphthalimide anchored to polymer, since the interaction of the amine group with a proton should be much favored in solution.

For the functionalized membranes, the response time of their fluorescence spectra to the extremely acidic environment was analyzed in the vapor phase, the results are shown in Figure 7. A high sensitivity to the acid vapor medium was observed in the absorbance and fluorescence spectra of naphthalimide $\mathbf{3 a}$ and $\mathbf{3 b}$ anchored to the polymer. In order to determine the effective change in absorption, it was necessary to maintain the film exposed to $\mathrm{HCl}$ vapors for approximately $35 \mathrm{~min}$, and $100 \mathrm{~min}$ were required to observe the fluorescence quenching. As it is showed in Figure 7A,B, both functionalized membranes are sensitive to acid vapor medium through their longest wavelength attributed to ICT absorption bands (Figure 7A,B). As it was observed in water, the $\mathrm{M}_{3 b}$ membrane exhibits better behavior in fluorescence decay under vapor treatment, Figure $7 \mathrm{D}$, than the $\mathrm{M}_{3 a}$ membrane (Figure 7C).

A)

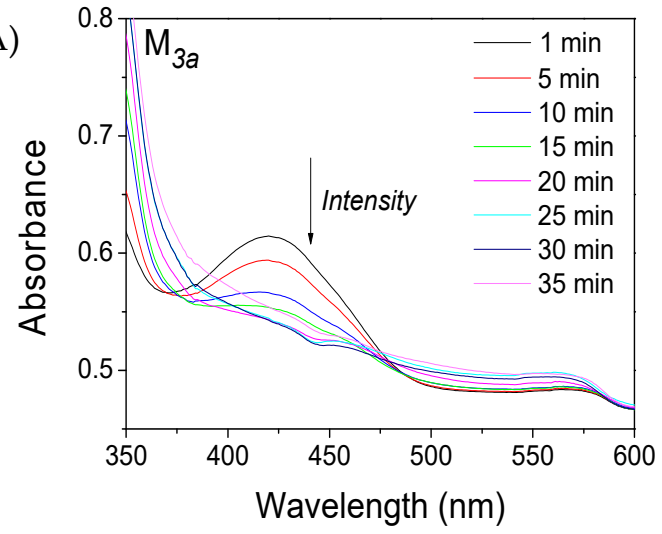

C)

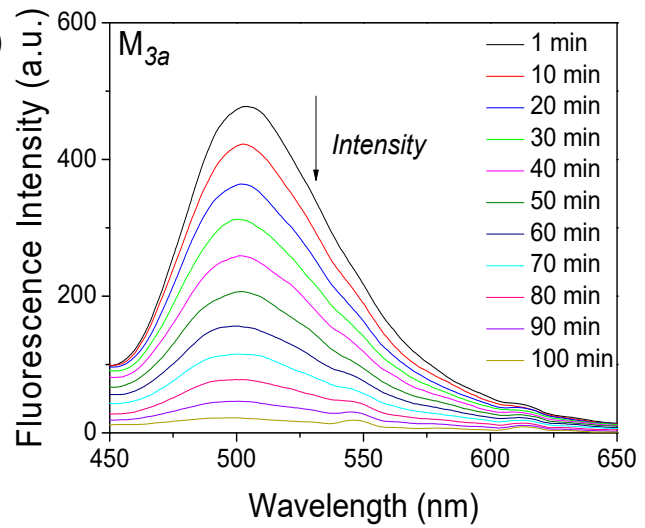

B)

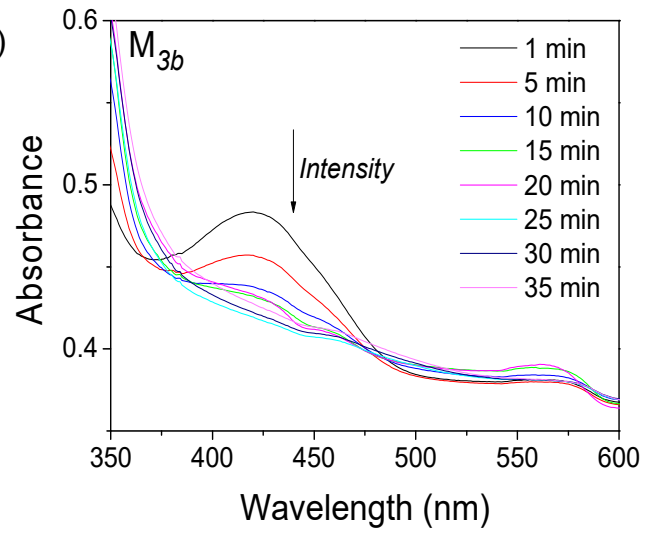

D)

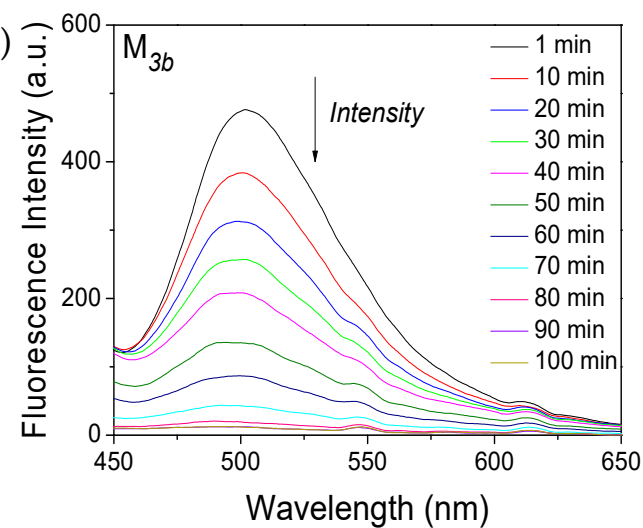

Figure 7. Absorption spectra for functionalized films $\mathrm{M}_{3 a}(\mathbf{A})$ and $\mathrm{M}_{3 b}(\mathbf{B})$ exposed to $\mathrm{HCl}$ vapors as a function of time (0-35 $\mathrm{min})$. Fluorescence spectra for $\mathrm{M}_{3 a}(\mathbf{C})$ and $\mathrm{M}_{3 b}(\mathrm{D})$ after $\mathrm{HCl}$ vapors treatment (0-100 min).

\section{Conclusions}

In this work, two monomers with a pending naphthalimide group attached to ethyl methacrylate by alkyl chains with different length were synthesized. Novel water-swollen photo-crosslinked membranes were obtained by copolymerization of the previously synthesized monomers with N-vinylpyrrolidone and butyl acrylate. The new solid sensors exhibited sensitive fluorescence changes at $\mathrm{pH}<3$. Because of the amine protonation of membranes, the decrease in absorbance and the quenching of fluorescence were observed. 
That behavior was related to the structure of naphthalimide substituents linked to the membrane. The time response was lower for membranes where the sensing group is linked through longer alkyl chain to the polymer matrix, and the interaction of the amine group with a proton should be much more favored. These results stress the importance of linker in the structure of fluorescent molecules for the preparation of polymer sensors with sufficient sensitivity to acidity. The material sensors showed a reversible behavior, which was evaluated by alternating their immersion in $\mathrm{HCl}(12 \mathrm{M})$ solution and in pure water along several cycles with enhancement/quenching of fluorescence. Moreover, the functionalized membranes were solids, and exhibited excellent properties for sensor applications, such as thermal stability, swelling in water, good manageability in terms of flexibility, optical transparency and dimensional stability, which are characteristics of great applied interest for the fabrication of an economical sensor for the acidity detection in aqueous environments.

Author Contributions: Conceptualization, J.L.P., F.C. and T.C.; formal analysis, J.L.P., E.H., F.C. and T.C.; investigation, J.L.P. and E.H.; writing-review and editing, J.L.P., F.C. and T.C. All authors have read and agreed to the published version of the manuscript.

Funding: This study was financed by MINECO (Project Ref. MAT2017-88923).

Institutional Review Board Statement: Not applicable.

Informed Consent Statement: Not applicable.

Data Availability Statement: Not applicable.

Conflicts of Interest: The authors declare no conflict of interest.

\section{References}

1. Wu, D.; Sedgwick, A.C.; Gunnlaugsson, T.; Akkaya, E.U.; Yoon, J.; James, T.D. Fluorescent chemosensors: The past, present and future. Chem. Soc. Rev. 2017, 46, 7105-7123. [CrossRef]

2. Oshchepkov, A.S.; Oshchepkov, M.S.; Oshchepkova, M.V.; Al-Hamry, A.; Kanoun, O.; Kataev, E.A. Naphthalimide-Based Fluorescent Polymers for Molecular Detection. Adv. Opt. Mater. 2021, 11, 2001913-2001943. [CrossRef]

3. Li, P.; Zhang, D.; Zhang, Y.; Lu, W.; Zhang, J.; Wang, W.; He, Q.; Théato, P.; Chen, T. Aggregation-Caused Quenching-Type Naphthalimide Fluorophores Grafted and Ionized in a 3D Polymeric Hydrogel Network for Highly Fluorescent and Locally Tunable Emission. ACS Macro Lett. 2019, 8, 937-942. [CrossRef]

4. Gudeika, D. A review of investigation on 4-substituted 1,8-naphthalimide derivatives. Synth. Met. 2020, 262, 116328. [CrossRef]

5. Poddar, M.; Sivakumar, G.; Misra, R. Donor-acceptor substituted 1,8-naphthalimides: Design, synthesis, and structure-property relationship. J. Mater. Chem. C 2019, 7, 14798-14815. [CrossRef]

6. Shaki, H.; Gharanjig, K.; Rouhani, S.; Khosravi, A. Synthesis and photophysical properties of some novel fluorescent dyes based on naphthalimide derivatives. J. Photochem. Photobiol. A 2010, 216, 44. [CrossRef]

7. Sanjuán, A.M.; Reglero Ruiz, J.A.; García, F.C.; García, J.M. Recent developments in sensing devices based on polymeric systems. React. Funct. Polym. 2018, 133, 103-125. [CrossRef]

8. Jiang, J.; Leng, B.; Xiao, X.; Zhao, P.; Tian, H. "Off-On-Off" fluorescent proton switch synthesized by RAFT polymerization. Polymer 2009, 50, 5681-5684. [CrossRef]

9. Hladysh, S.; Murmiliuk, A.; Vohlídal, J.; Zedník, J. Attachment of a 1,8-Naphthalimide Moiety to a Conjugated Polythiophene Efficiently Improves the Sensing Abilities of Naphthalimide-Based Materials. Macromol. Chem. Phys. 2019, 220, 1800436-1800446. [CrossRef]

10. He, H.; Mortellaro, M.A.; Leiner, M.J.P.; Fraatz, R.J.; Tusa, J.K. A Fluorescent Sensor with High Selectivity and Sensitivity for Potassium in Water. J. Am. Chem. Soc. 2003, 125, 1468-1469. [CrossRef]

11. Lei, S.; Meng, X.; Wang, L.; Zhou, J.; Qin, D.; Duan, H. A Naphthalimide-Based Fluorescent Probe for the Detection and Imaging of Mercury Ions in Living Cells. Chem. Open 2021, 10, 1116-1122. [CrossRef] [PubMed]

12. Udhayakumari, D. Detection of toxic fluoride ion via chromogenic and fluorogenic sensing. A comprehensive review of the year 2015-2019. Spectrochim. Acta Part A 2020, 228, 117817-117850. [CrossRef] [PubMed]

13. Zhang, Z.; Feng, Q.; Yang, M.; Tang, Y. A ratiometric fluorescent biosensor based on conjugated polymers for sensitive detection of nitroreductase and hypoxia diagnosis in tumor cells. Sens. Actuators B 2020, 318, 128257-128265. [CrossRef]

14. Huang, S.; Han, R.; Zhuang, Q.; Liu, Y. New photostable naphthalimide-based fluorescent probe for mitochondrial imaging and tracking. Biosens. Bioelectron. 2015, 71, 313-321. [CrossRef]

15. Li, P.; Zhang, D.; Zhang, Y.; Lu, W.; Wang, W.; Chen, T. Ultrafast and Efficient Detection of Formaldehyde in Aqueous Solutions Using Chitosan-based Fluorescent Polymers. ACS Sens. 2018, 3, 2394-2401. [CrossRef] [PubMed] 
16. Un, H.; Wu, S.; Huang, C.B.; Xuc, Z.; Xu, L. A naphthalimide-based fluorescent probe for highly selective detection of histidine in aqueous solution and its application in in vivo imaging. Chem. Commun. 2015, 15, 3143-3146. [CrossRef] [PubMed]

17. Staneva, D.; Vasileva-Tonkova, E.; Grozdanov, P.; Vilhelmova-llieva, N.; Nikolova, I.; Grabchev, I. Synthesis and photophysical characterisation of 3-bromo-4-dimethylamino-1,8-naphthalimides and their evaluation as agents for antibacterial photodynamic therapy. J. Photochem. Photobiol. A Chem. 2020, 401, 112730-112737. [CrossRef]

18. Fernández-Alonso, S.; Corrales, T.; Pablos, J.L.; Catalina, F. Solid fluorescence sensors obtained by functionalization of photocrosslinked water-swollen acrylic membranes with 4-piperazine naphthalimide derivatives. Polymer 2017, 12, 139-150. [CrossRef]

19. Fernández-Alonso, S.; Corrales, T.; Pablos, J.L.; Catalina, F. A Switchable fluorescence solid sensor for $\mathrm{Hg}^{2+}$ detection in aqueous media based on a photocrosslinked membrane functionalized with (benzimidazolyl)methyl-piperazine derivative of 1,8-naphthalimide. Sens. Actuators B. Chem. 2018, 270, 256-262. [CrossRef]

20. Grabchev, I.; Qian, X.; Xiao, Y.; Zhang, R. Novel heterogeneous PET fluorescent sensors selective for transition metal ions or protons: Polymers regularly labelled with naphthalimide. New J. Chem. 2002, 26, 920-925. [CrossRef]

21. Tian, Y.; Su, F.; Weber, W.; Nandakumar, V.; Shumway, B.R.; Jin, Y.; Zhou, X.; Holl, M.R.; Johnson, R.H.; Meldrum, D.R. A series of naphthalimide derivatives as intra and extracellular pH sensors. Biomaterials 2010, 31, 7411-7422. [CrossRef] [PubMed]

22. Jiang, J.; Xiao, X.; Zhao, P.; Tian, H. Colorimetric naked-eye recognizable anion sensors synthesized via RAFT polymerization. J. Polym. Sci. Part A Polym. Chem. 2010, 48, 1551-1556. [CrossRef]

23. Zhou, L.; Lv, F.; Liu, L.; Wang, S. Water-Soluble Conjugated Organic Molecules as Optical and Electrochemical Materials for Interdisciplinary Biological Applications. Acc. Chem. Res. 2019, 52, 3211-3222. [CrossRef] [PubMed]

24. Fernández-Alonso, S.; Corrales, T.; Pablos, J.L.; Catalina, F. Surface modification of poly(ethylene-butyl acrylate) copolymers by microwave methodology and functionalization with 4-dimethylamino-N-(2-hydroxyethyl)-1,8-naphthalimide for acidity sensing. React. Funct. Polym. 2016, 107, 78-86. [CrossRef]

25. Pagac, M.; Haiyins, J.; Ma, Q.; Jancar, L.; Jansa, J.; Stefek, P.; Mesicek, J. A Review of Vat Photopolymerization Technology: Materials, Applications, Challenges, and Future Trends of 3D Printing. Polymers 2021, 13, 598. [CrossRef]

26. Larraza, I.; Peinado, C.; Abrusci, C.; Catalina, F.; Corrales, T. Hyperbranched polymers as clay surface modifiers for UV-cured nanocomposites with antimicrobial activity. J. Photochem. Photobiol. A Chem. 2011, 224, 46-54. [CrossRef]

27. Jagtap, A.; More, A. A review on self-initiated and photoinitiator-free system for photopolymerization. Polym. Bull. 2021, 11, 2874. [CrossRef]

28. Dumur, F. Recent advances on visible light photoinitiators of polymerization based on Indane-1,3-dione and related derivatives. Eur. Polym. J. 2021, 143, 110178-110200. [CrossRef]

29. Allen, N.S.; Corrales, T.; Edge, M.; Catalina, F.; Blanco-Pina, M.; Green, A. Photochemistry and photopolymerization activities of novel phenylthiobenzophenone and diphenylthiophene photoinitiators. Polymer 1998, 39, 903-909. [CrossRef]

30. Redondo-Foj, B.; Carsí, M.; Ortiz-Serna, P.; Sanchis, M.J.; Vallejos, S.; García, F.; García, J.M. Effect of the Dipole-Dipole interactions in the molecular dynamics of poly(vinylpyrrolidone)-based copolymers. Macromolecules 2014, 47, 5334-5346. [CrossRef]

31. Panchencko, A.; Fedorova, O.A.; Fedorov, Y.V. Fluorescent and colorimetric chemosensors for cations based on 1,8-naphthalimide derivatives: Design principles and optical signalling mechanisms. Russ. Chem. Rev. 2014, 83, 155-164. [CrossRef]

32. Zamarreño, C.R.; Bravo, J.; Goicoechea, J.; Matias, I.R.; Arregui, F.J. Response time enhancement of pH sensing films by means of hydrophilic nanostructured coatings. Sens. Actuators B 2007, 128, 138-144. [CrossRef]

33. Frankær, C.G.; Sørensen, T.J. Investigating the Time Response of an Optical pH Sensor Based on a Polysiloxane-Polyethylene Glycol Composite Material Impregnated with a pH-Responsive Triangulenium Dye. ACS Omega 2019, 4, 8381-8389. [CrossRef] [PubMed] 